\title{
PREDIÇÃO DO RISCO DE QUEDAS EM IDOSOS QUE VIVEM NO DOMICILIO
}

Zoila Esperanza Leitón Espinoza, Universidad Nacional de Trujillo, Peru. E-mail: zoilaleiton@gmail.com Jack Roberto Silva Fhon, Universidade de São Paulo, Brasil. E-mail: betofhon@usp.br Rosalina Aparecida Partezani Rodrigues, Universidade de São Paulo, Brasil. E-mail: rosalina@eerp.usp.br Fabia Maria de Lima, Universidade de Pernambuco, Brasil. E-mail: fabia.lima@upe.br Wilmer Luis Fuentes Neira, Hospital de Emergencias Grau, EsSalud, Peru. E-mail: sriwilpi@gmail.com Maritza Evangelina Villanueva Benites, Universidad Nacional de la Amazonia Peruana, Peru. E-mail: maritza.villanuevabenites@gmail.com

\section{RESUMO}

Introdução: A queda é uma causa comum de morbimortalidade em idosos. Apresenta uma prevalência de 20-30\% sendo importante a identificação dos diferentes fatores de risco na avaliação pelo profissional de saúde. Objetivo: determinar a predição do risco de quedas no idoso que vive no domicilio. Métodos: Estudo transversal com 1110 idosos do município de La Libertad, Peru. Avaliou-se o estado cognitivo, sintomas depressivos, capacidade funcional, quedas nos últimos 12 meses, doenças autorreferidas, número de medicamentos, equilíbrio estático e dinâmico. Construiu-se modelos de regressão logística em camada. As probabilidades previstas de alguma queda ou queda recorrente foram usadas para construir curvas ROC. As AUC foram calculadas para avaliar o desempenho preditivo de cada modelo com $\mathrm{p}<0,05$. O estudo foi aprovado pelo comitê de ética da Universidade de Trujillo. Resultados: dos que sofreram queda houve predomínio do sexo feminino, idosos mais jovens, tinham companheiro e viviam sozinhos. Ademais, não tinham déficit cognitivo, dependência funcional, com sintomas depressivos e com alteração do equilíbrio dinâmico. Dos modelos em camadas, o melhor modelo foi o quarto, em que aqueles que sofreram alguma queda os fatore preditivos foram ser mulher, viver só, maior número de doenças e consumo de medicamentos, e dependência funcional. Os fatores preditivos para quedas recorrentes foram viver só, maior consumo de medicamentos e dependência para as atividades instrumentais da vida diária. Conclusão: os achados demonstram que fatores intrínsecos e extrínsecos tem que ser avaliados constantemente pelo enfermeiro com a finalidade de diminuir os riscos de sofrer queda.

Palavras-chave: Idoso; Acidente por quedas; Estudos transversais; Previsões; Peru. 